\title{
Urinary BPA measurements in children and mothers from six European member states: Overall results and determinants of exposure
}

\author{
Adrian Covaci ${ }^{\mathrm{a}, *}$, Elly Den Hond ${ }^{\mathrm{b}}$, Tinne Geens ${ }^{\mathrm{a}}$, Eva Govarts ${ }^{\mathrm{b}}$, Gudrun Koppen ${ }^{\mathrm{b}}$, \\ Hanne Frederiksen ${ }^{c}$, Lisbeth E. Knudsen ${ }^{d}$, Thit A. Mørck ${ }^{\mathrm{d}}$, Arno C. Gutleb ${ }^{\mathrm{e}}$, \\ Cedric Guignard ${ }^{\mathrm{e}}$, Emanuelle Cocco $^{\mathrm{e}}$, Milena Horvat ${ }^{\mathrm{f}}$, Ester Heath ${ }^{\mathrm{f}}$, Tina Kosjek ${ }^{\mathrm{f}}$, \\ Darja Mazej $^{\mathrm{f}}$, Janja Snoj Tratnik ${ }^{\mathrm{f}}$, Argelia Castaño ${ }^{\mathrm{g}}$, Marta Esteban ${ }^{\mathrm{g}}$, Francisco Cutanda ${ }^{\mathrm{g}}$, \\ Juan José Ramos ${ }^{g}$, Marika Berglund ${ }^{\mathrm{h}}$, Kristin Larsson ${ }^{\mathrm{h}}$, Bo A.G. Jönsson ${ }^{\mathrm{i}}$, Pierre Biot $^{\mathrm{j}}$, \\ Ludwine Casteleyn $^{\mathrm{k}}$, Reinhard Joas ${ }^{1}$, Anke Joas ${ }^{1}$, Louis Bloemen ${ }^{\mathrm{m}}$, Ovnair Sepai ${ }^{\mathrm{n}}$, \\ Karen Exley $^{\mathrm{n}}$, Greet Schoeters ${ }^{\mathrm{b}, \mathrm{o}, \mathrm{p}}$, Jürgen Angerer ${ }^{\mathrm{q}}$, Marike Kolossa-Gehring ${ }^{\mathrm{r}}$, \\ Ulrike Fiddicke $^{\mathrm{r}}$, Dominique Aerts ${ }^{\mathrm{j}}$, Holger M. Koch ${ }^{\mathrm{q}}$
}

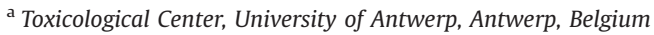

${ }^{\mathrm{b}}$ Flemish Institute for Technological Research (VITO), Environmental Risk and Health Unit, Mol, Belgium

${ }^{\mathrm{c}}$ University Department of Growth and Reproduction, Rigshospitalet, Denmark

d University of Copenhagen, Copenhagen, Denmark

e Centre de Recherche Public - Gabriel Lippmann, Luxembourg, Luxembourg

f Jožef Stefan Institute, Ljubljana, Slovenia

${ }^{g}$ Instituto de Salud Carlos III (ISCIII), Madrid, Spain

${ }^{\mathrm{h}}$ Karolinska Institutet, Stockholm, Sweden

${ }^{\mathrm{i}}$ Lund University, Lund, Sweden

${ }^{j}$ Federal Public Service Health, Food Chain Safety and Environment, Brussels, Belgium

${ }^{\mathrm{k}}$ University of Leuven, Leuven, Belgium

${ }^{1}$ BiPRO GmbH, Munich, Germany

${ }^{\mathrm{m}}$ Environmental Health Science International, Amsterdam, The Netherlands

${ }^{n}$ Public Health England, London, United Kingdom

${ }^{\circ}$ Department of Biomedical Sciences, University of Antwerp, Antwerp, Belgium

p University of Southern Denmark, Odense, Denmark

${ }^{\mathrm{q}}$ Institute of Prevention and Occupational Medicine of the German Social Accident Insurance, Institute of the Ruhr University, Bochum, Germany

${ }^{\mathrm{r}}$ Federal Environment Agency, Berlin, Germany

\section{A R T I C L E I N F O}

\section{Article history:}

Received 24 May 2014

Received in revised form

23 July 2014

Accepted 5 August 2014

Keywords:

Bisphenol-A

Human exposure

Human biomonitoring

Europe

Mother-children pairs

\begin{abstract}
A B S T R A C T
For the first time in Europe, both European-wide and country-specific levels of urinary Bisphenol A (BPA) were obtained through a harmonized protocol for participant recruitment, sampling and quality controlled biomarker analysis in the frame of the twin projects COPHES and DEMOCOPHES. 674 childmother pairs were recruited through schools or population registers from six European member states (Belgium, Denmark, Luxembourg, Slovenia, Spain and Sweden). Children (5-12 y) and mothers donated a urine sample. Information on socio-demographic characteristics, life style, dietary habits, and educational level of the parents was provided by mothers. After exclusion of urine samples with creatinine values below $300 \mathrm{mg} / \mathrm{L}$ or above $3000 \mathrm{mg} / \mathrm{L}, 653$ children and 639 mothers remained for which BPA was measured. The geometric mean (with 95\% confidence intervals) and 90th percentile were calculated for BPA separately in children and in mothers and were named "European reference values". After adjustment for confounders (age and creatinine), average exposure values in each country were compared with the mean of the "European reference values" by means of a weighted analysis of variance. Overall geometric means of all countries (95\% CI) adjusted for urinary creatinine, age and gender were $2.04(1.87-2.24) \mu \mathrm{g} / \mathrm{L}$ and $1.88(1.71-2.07) \mu \mathrm{g} / \mathrm{L}$ for children $(n=653)$ and mothers $(n=639)$, respectively. Multiple regression analysis was used to identify significant environmental, geographical,
\end{abstract}

\footnotetext{
* Corresponding author.

E-mail address: adrian.covaci@uantwerpen.be (A. Covaci).
} 
personal or life style related determinants. Consumption of canned food and social class (represented by the highest educational level of the family) were the most important predictors for the urinary levels of BPA in mothers and children. The individual BPA levels in children were significantly correlated with the levels in their mothers $(r=0.265, p<0.001)$, which may suggest a possible common environmental/ dietary factor that influences the biomarker level in each pair. Exposure of the general European population was well below the current health-based guidance values and no participant had BPA values higher than the health-based guidance values.

(c) 2014 Elsevier Inc. All rights reserved.

\section{Introduction}

Bisphenol-A (BPA) is used in the manufacturing of plastics, mostly polycarbonate (used in food contact materials and many other plastic consumer products) and epoxy resins used in the coating of food and drink cans. Other typical application areas are paints, varnishes, glues, or thermal paper used for receipts (Geens et al., 2011, 2012). Due to the widespread use in plastics and other consumer products, human exposure to BPA occurs for every individual (Geens et al., 2012). BPA is rapidly metabolized in the human body and is quickly eliminated in urine, where it can be measured at $\mu \mathrm{g} / \mathrm{L}$ levels (Geens et al., 2012). Urinary BPA provides thus a measure of recent exposure, i.e. the last few hours up to a couple of days. However, BPA metabolism and half-life are dependent on the routes of exposure. Rapid metabolism is observed for oral exposure, while other types of exposure (which avoid first pass liver metabolism) may result in longer residence time of BPA in the blood stream (Vandenberg et al., 2007)

Current exposure levels to BPA in the general population are relatively low, with geometric means or medians of $<0.1 \mu \mathrm{g} / \mathrm{kg}$ body weight per day for the total intake of BPA calculated from biomonitoring data in different countries (summarized in Geens et al. (2012)). These BPA intakes are well below the current tolerable daily intake (TDI) of $50,000 \mathrm{ng} / \mathrm{kg}$ body weight (bw) per day as established by the European Food Safety Authority (EFSA). Recently, EFSA has launched an open consultation on its draft opinion on the potential health risks of BPA (EFSA, 2014). This includes a temporary reduction of the TDI (t-TDI) to $5000 \mathrm{ng} / \mathrm{kg}$ bw per day and the consideration of exposure to BPA from both dietary and non-dietary sources.

However, human health effects from low-level exposure to BPA remain under discussion; whether continuous exposure to BPA may affect the hormonal system (as so act as an endocrinedisruptor chemical) is currently being debated (Hengstler et al., 2011; Teeguarden and Hanson-Drury, 2013; EFSA, 2014). Yet, more research is needed to assess the health effects of long-term exposure to low levels of BPA.

A centrally developed protocol to perform a human biomonitoring (HBM) feasibility study at European level on mercury, cotinine, cadmium, phthalates and BPA in 6-11 year old children and their mothers was developed as part of the COPHES FP7 project (Becker et al., 2014). The protocol was translated and applied in 17 European countries in the DEMOCOPHES LIFE+ project, the pilot study to perform HBM in Europe via a harmonized approach (Casteleyn et al., 2014). Rigorous quality assessment and assurance within COPHES/DEMOCOPHES guaranteed the accuracy and international comparability of analytical results (Schindler et al., 2014). The results of the central analysis and their interpretation of BPA levels obtained in 6 out of the 17 countries implementing DEMOCOPHES are presented in the current paper.

This paper presents exposure levels of BPA in and within Europe obtained via harmonized HBM, basic data on the distribution of BPA among selected sub-groups of the general population, along with the major determinants of exposure and the relationship of measured BPA levels to guidance values.

\section{Materials and methods}

\subsection{Study population}

BPA was included as an optional biomarker in the DEMOCOPHES project and was measured in six member states, i.e. in Belgium, Denmark, Luxembourg Slovenia, Spain, and Sweden. A cross-sectional study was designed to assess exposure in a pre-determined number of children and their mothers per country and from two areas per country with differing degrees of urbanization. Since the selected populations are not representative for their country, the results of BPA can thus not be considered as European reference values and should be interpreted within the limitations of the study design. However, they provide a first estimate of the exposure in European children and their mothers, and will therefore be referred to as preliminary European reference values. Originally, the two target populations were children (age group of 6-11 years) and their accompanying mothers, representing, with a few exceptions, women of childbearing age (up to 45 years of age). A small number of mothers were over 45 years due to difficulties to reach the target sample size in some countries.

Within each country, the target sample size was 240 participants, i.e. 120 children and 120 mothers, except in Luxembourg where the target was set at 120 subjects (60 children and 60 mothers) because of its small population size. Inclusion criteria were the following: i) both mother and child needed sufficient language ability in the national language in order to understand the study protocol and to be able to fill in the questionnaires; ii) both mother and child had to live in the study area for at least five years; iii) the child should live with the mother for the majority of the time ( $>16$ days/month), and iv) only one child per mother (randomly selected) could be included in the study. Exclusion criteria were the following: i) mothers or children living in hospitals, institutions or being homeless; ii) mothers or children having metabolic disturbances or abnormal urine excretion.

Mother-child pairs were recruited from two different study areas selected according to the degree of urbanization using the upper and lower categories within a country; thus leading to the selection of a densely populated area, which is referred to as the 'urban area', and an area with low population density, the socalled 'rural area'. The children were the primary target group, and therefore selection was done at the level of the child. Each country had the option either to select the children through the population registries, or to contact the children via their schools. Five of the six countries recruited participants through schools; one country used both population registries and schools. All participants gave informed consent and the human subjects' approval was obtained by each involved institute.

All first-morning urine samples were collected between September 2011 and February 2012 in urinary vessels, prewashed with 10\% nitric acid. All countries were instructed to collect complete urine samples in one container and selected the appropriate size of urine container for this purpose. Urine samples were kept at $4-8{ }^{\circ} \mathrm{C}$ during the field work, aliquoted within $24 \mathrm{~h}$ and stored at $-20{ }^{\circ} \mathrm{C}$ until analysis. Questionnaire information on personal characteristics and exposure pathways of the child and the mother was obtained in an in-person interview with the mother, either during a home visit or at the examination center.

\subsection{Analysis and quality assurance}

Per country, urine samples were analyzed in one laboratory which used methods validated in-house and participated in the COPHES/DEMOCOPHES External Quality Assessment exercises. Interlaboratory Comparison Investigation (ICI) exercises were organized for the measurement of BPA in urine to allow the harmonization of analytical methods and to improve the results' comparability. Laboratories reported their results in around five weeks after receiving the test samples and, after the evaluation by COPHES QAU (Quality Assurance Unit), the results were discussed through a web conference with all participants. BPA was incorporated in the ICI/EQUAS scheme during the 2nd ICI round (02/2011) from May to July 2011. BPA was further evaluated in the 3rd ICI round (03/2011), which was an External Quality Assessment (EQUAS 1) and took place from September to November 2011 and in the EQUAS 2 (December 2011 to February 2012). In order to be accepted as DEMOCOPHES lab to perform the analyses of BPA in urine samples, the laboratories had to successfully participate in at least one ICI and one EQUAS or two EQUAS rounds. In both EQUAS 1 and EQUAS 2 performed during the measurement campaign of DEMOCOPHES, the RSDs of the qualified labs $(n=5)$ were $20.5 \%$ and $13.5 \%$ for the low conc. control samples $(1.48 \mu \mathrm{g} / \mathrm{L}$ and $3.01 \mu \mathrm{g} / \mathrm{L}$, 
respectively) and $17.8 \%$ and $19.0 \%$ for the high conc. control samples (35.6 $\mu \mathrm{g} / \mathrm{L}$ and $11.9 \mu \mathrm{g} / \mathrm{L}$, respectively).

Among laboratories which have qualified to analyzed BPA in the DEMOCOPHES urine samples, five labs used LC-MS/MS (with LOQs between 0.11 and $1.0 \mu \mathrm{g} / \mathrm{L}$ ), while one lab used GC-(ECNI)MS with an LOQ of $0.2 \mu \mathrm{g} / \mathrm{L}$. Laboratories reported their results as total urinary BPA (after enzymatic hydrolysis). However, quality assurance was set to monitor both total and free BPA to check for possible blank issues by free BPA. More details on the participating laboratories and the specific procedures for quality assurance are presented in Schindler et al. (2014).

\subsection{Statistical analysis}

Database management and statistical analyses were done with $\mathrm{R}$ software version 2.12.1 (R Development Core Team, 2012) and SAS software version 9.3 (SAS Institute Inc.). For the individual databases, samples below the limit of quantification (LOQ) were replaced by $1 / 2 \mathrm{LOQ}$. The WHO criterion on spot urine samples was applied, i.e. samples with a creatinine concentration lower than $300 \mathrm{mg} / \mathrm{L}$ or higher than $3000 \mathrm{mg} / \mathrm{L}$ were excluded from the analysis (WHO, 1996).

European reference values (geometric means $(95 \% \mathrm{CI})$ and 90 th percentiles) for BPA were calculated for unadjusted data, and after adjustment for pre-selected confounders of BPA (creatinine, age and gender for children and creatinine and age for mothers). These reference values were calculated separately for mothers and children in $\mu \mathrm{g} / \mathrm{L}$ and in $\mu \mathrm{g} / \mathrm{g}$ creatinine. To adjust for unequal sample numbers per country, a weighted geometric mean and a weighted 90th percentile was calculated. All countries were weighted in such a way that they contributed 120 participants, except Luxembourg that contributed 60 participants per subpopulation. In order to compare the BPA levels among countries, the overall differences were tested in multiple regression models (based on F-test), either with and without inclusion of confounders. If an overall significant difference was observed $(p<0.05)$, further testing was done by comparing the mean in each member state with the mean "European reference value" by using multiple regression models, both with and without inclusion of confounders.

In order to identify determinants of exposure, in the first step, univariate models were developed for selected confounders and covariates (Table 1). In the second step, multiple regression models were built including those determining factors which are significant at the 0.25 significance level in the univariate analyses and pre-specified confounders fixed into the model. The final models were selected by stepwise selection procedures, in which " $p$ " was set at 0.05 for a variable to stay in the model. Linear mixed models were used to take into account the clustered design of sampling within member states.

The assumption of normality was checked with informal diagnostic residual plots and the Kolmogorov-Smirnov test (Neter et al., 1996). Influence diagnostics (e.g. restricted likelihood distance, Cook's $D$, and CovRatio) were used to quantify the influence of one or more observations by computing parameters estimates based on all data points, removing the cases in question from the data, refitting the model, and computing statistics based on the change between full-data and reduced-data estimates (Fox, 1991). Simple plots were produced (child in $Y$-axis and mothers in $X$-axis) for BPA in the same units for mothers and children. Spearman correlation coefficients were calculated.

\section{Results and discussion}

\subsection{Description of study population}

The basic characteristics of the participating children and their mothers for the six European countries are given in Table 1. Within the study population of the children, there was an equal distribution between boys and girls (50.1\% vs. $49.9 \%$ ) and between the different age groups ( $48.6 \%$ from 5 to 8 years vs. $51.4 \%$ from 9 to 12 years). Also, with respect to area, there was a near equal distribution between rural (50.7\%) and urban (49.3\%) samples (Table 1). The good equilibrium among gender classes, age groups and area demonstrates that the stratification strategy was successfully applied by all member states. More than $40 \%$ of the mothers (41.8\%) were above 40 years, showing that in several countries, the inclusion criterion of a maximum age of 45 years was a difficult target to reach. The oldest mother sampled was 52 year. The body mass index distribution of mothers was in accordance with the expected data for a young to medium-age female population, with $70.4 \%$ of the mothers having a body mass index (BMI) $<25 \mathrm{~kg} / \mathrm{m}^{2}$.

Table 1

Descriptive statistics of children $(n=653)$ and mothers $(n=639)$ from six European member states.

\begin{tabular}{|c|c|c|c|c|}
\hline & \multicolumn{2}{|l|}{ Children $(n=653)$} & \multicolumn{2}{|l|}{ Mothers $(n=639)$} \\
\hline & Categories & $N(\%)$ & Categories & $N(\%)$ \\
\hline \multirow[t]{2}{*}{ Gender } & Boy & $327(50.1 \%)$ & Woman & $639(100 \%)$ \\
\hline & Girl & $326(49.9 \%)$ & & \\
\hline \multirow[t]{3}{*}{ Age } & $5-8$ years & 317 (48.6\%) & $\leq 35$ years & $93(14.6 \%)$ \\
\hline & 9-12 years & $335(51.4 \%)$ & $35-40$ years & $279(43.7 \%)$ \\
\hline & & & $>40$ years & $267(41.8 \%)$ \\
\hline \multirow[t]{3}{*}{ Body mass index } & $\mathrm{BMI}<15 \mathrm{~kg} / \mathrm{m}^{2}$ & $165(26.3 \%)$ & Normal weight $\left(\mathrm{BMI}<25 \mathrm{~kg} / \mathrm{m}^{2}\right)$ & $442(70.4 \%)$ \\
\hline & BMI: $15-17 \mathrm{~kg} / \mathrm{m}^{2}$ & $227(36.2 \%)$ & Overweight (BMI: $25-30 \mathrm{~kg} / \mathrm{m}^{2}$ ) & $123(19.6 \%)$ \\
\hline & $\mathrm{BMI} \geq 17 \mathrm{~kg} / \mathrm{m}^{2}$ & $235(37.5 \%)$ & Obesity (BMI $\left.\geq 30 \mathrm{~kg} / \mathrm{m}^{2}\right)$ & $62(10.0 \%)$ \\
\hline \multirow[t]{2}{*}{ Area of residence } & Rural & $331(50.7 \%)$ & Rural & $324(50.7 \%)$ \\
\hline & Urban & $322(49.3 \%)$ & Urban & $315(49.3 \%)$ \\
\hline \multirow[t]{3}{*}{ Highest educational level of the family } & Primary (ISCED 0-2) & $47(7.2 \%)$ & Primary (ISCED 0-2) & $46(7.2 \%)$ \\
\hline & Secondary (ISCED 3-4) & $136(20.9 \%)$ & Secondary (ISCED 3-4) & $132(20.7 \%)$ \\
\hline & Tertiary (ISCED 5-6) & 469 (71.9\%) & Tertiary (ISCED 5-6) & $460(72.1 \%)$ \\
\hline \multirow[t]{2}{*}{ First-morning urine samples } & Yes & $646(98.9 \%)$ & Yes & $627(98.1 \%)$ \\
\hline & No & $7(1.1 \%)$ & No & $12(1.9 \%)$ \\
\hline \multirow[t]{3}{*}{ Period of urine sampling ${ }^{\mathrm{a}}$} & $<10 \mathrm{~h}$ & $235(36.4 \%)$ & $<7 \mathrm{~h}$ & $188(30.1 \%)$ \\
\hline & $10-11 \mathrm{~h}$ & $235(36.4 \%)$ & $7-9 \mathrm{~h}$ & $341(54.6 \%)$ \\
\hline & $\geq 11 \mathrm{~h}$ & 175 (27.1\%) & $\geq 9 \mathrm{~h}$ & $96(15.4 \%)$ \\
\hline \multirow[t]{4}{*}{ Urinary creatinine (mg/L) } & $N$ & 1842 & $N$ & 1839 \\
\hline & Median & 1053 & Median & 1163 \\
\hline & P25-75 & $784-1426$ & P25-75 & $781-1618$ \\
\hline & Min-Max & $10-3120$ & Min-Max & $57-3670$ \\
\hline \multirow[t]{4}{*}{ Smoking habits } & Smoker & $0(0 \%)$ & Daily smoker & $70(11.0 \%)$ \\
\hline & Non-smoker & $653(100 \%)$ & Occasional smoker & $30(4.7 \%)$ \\
\hline & & & Former smoker & $164(25.7 \%)$ \\
\hline & & & Never smoker & 375 (58.7\%) \\
\hline \multirow[t]{2}{*}{ Consumption of canned food } & Several times/month & $84(17.4 \%)$ & Several times/month & $101(21.2 \%)$ \\
\hline & Once a month or less & $398(82.6 \%)$ & Once a month or less & $376(78.8 \%)$ \\
\hline \multirow{2}{*}{ Consumption of convenience food in last $24 \mathrm{~h}$} & Yes & $241(37.5 \%)$ & Yes & $267(42.6 \%)$ \\
\hline & No & $401(62.5 \%)$ & No & $360(57.4 \%)$ \\
\hline
\end{tabular}

P25: 25th percentile; P75: 75th percentile; N: number; ISCED: International Standard Classification of Education.

a Period of time between the last urination and the sample collection. 
The vast majority of the urine samples that were collected (98.9\% in children and $98.1 \%$ in mothers) were first morning urine samples; the others were spot urines that were collected throughout the day. In the initial protocol, measurement of the total volume of the urine samples was foreseen. However, in several countries, the information on volume was not reliable because sample containers were too small and thus did not represent the volumes of the morning urination. Therefore, the data on volume were not used in the analysis.

None of the children in the study population were smokers, or at least they reported that they did not smoke. $15.7 \%$ of the mothers were current smokers, i.e. $11.0 \%$ smoked daily and $4.7 \%$ occasionally. Smoking habits in mothers differed considerably by country, with low proportions $(<10 \%)$ of current smokers in Luxembourg (8.3\%) and Belgium (9.3\%), but high proportions $(>30 \%)$ in Spain (36.6\%). About one fifth of the participants (17.4\% of the children and $21.2 \%$ of the mothers) reported to eat canned food several times per month, while $37.5 \%$ of the children and $42.6 \%$ of the mothers had consumed convenience food in the last $24 \mathrm{~h}$.

\subsection{Comparison within and outside Europe}

The raw, unadjusted data per member state for children and mothers are given in Table 2 and Table SI-1. The LOQs in the different countries ranged from 0.11 to $1 \mu \mathrm{g} / \mathrm{L}$. The proportion of values $>$ LOQ (or the detection frequency) was $>90 \%$ in 5 out of 6 countries; it was around 50\% in Luxembourg, the country with the highest LOQ i.e. $1 \mu \mathrm{g} / \mathrm{L}$. The linear regression model assumptions of normality, constancy of variance and independence were checked and were fulfilled for the final models without influential outliers both for children and adults.

To allow a statistical comparison of the data, the geometric mean of each individual member state was compared with the European mean (based on six countries). In this comparison, data were weighted for an equal number of participants in each country (120, except 60 in Luxembourg). Comparisons were performed for BPA expressed in $\mu \mathrm{g} / \mathrm{L}$ and in $\mu \mathrm{g} / \mathrm{g}$ creatinine, both on unadjusted data and after adjustment for confounders (age, gender (+ urinary creatinine for data in $\mu \mathrm{g} / \mathrm{L}$ ) in children; age ( + urinary creatinine for data in $\mu \mathrm{g} / \mathrm{L}$ ) in mothers). Results in both units, and without or with adjustment, gave very similar results, both in children and in mothers.
Overall, there was a low inter-individual variability in urinary BPA levels: i) the distribution within a country was narrow; ii) levels were quite similar in children and in mothers; and iii) the average levels in the different countries were very close together (ratio between highest and lowest geometric mean was 1.8 in children and 2.0 in mothers). Yet, significant differences were observed between countries (Table 2, Table SI-1). In children, compared to the European mean, significantly higher values were observed in Slovenia and significantly lower levels were found in Sweden (Table 2, Fig. 1). For the mothers, significantly higher concentrations were observed in Belgium and Denmark, while levels in Sweden and Slovenia were significantly lower (Table 2, Fig. 1). Thus, the conclusions in both age groups are to some extent consistent (e.g. for Sweden), but also contradictory (e.g. for Slovenia). We may speculate that the correlation between mothers and children will be high in case the major source of BPA is a common life style factor such as the food consumption pattern of the family, but the correlation will be weaker if exposure to BPA is rather determined by individual habits such as use of medication, consumption of convenience food or use of different types of packing material, which may differ between children and mothers.

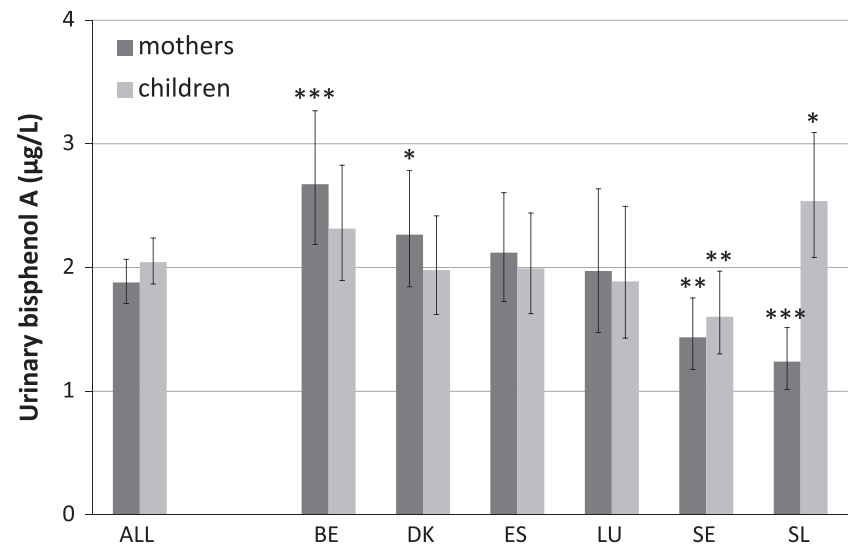

Fig. 1. Mean urinary BPA concentration in six countries in comparison with the European reference value. Data are geometric means $(95 \% \mathrm{CI})$ in $\mu \mathrm{g} / \mathrm{L}$, after adjustment for urinary creatinine and age in mothers, and additional adjustment for gender in children. ALL: six countries; BE: Belgium; DK: Denmark; ES: Spain; LU: Luxembourg; SE: Sweden; and SL: Slovenia. The overall p-Value (ANOVA): $p<0.0001$ in mothers; $p=0.04$ in children. Post-hoc analysis: each country is compared with the European reference value (ALL); ${ }^{*} p<0.05$; $* * p<0.01$; and $* * * p<0.001$.

Table 2

Results of urinary BPA $(\mu \mathrm{g} / \mathrm{L})$ per member state in children and their mothers, unadjusted data.

\begin{tabular}{|c|c|c|c|c|c|c|c|c|c|c|c|c|}
\hline Member state & $N$ & LOQ & $\%>$ LOQ & GM $(95 \%$ CI) & Min. & P10 & P25 & P50 & P75 & P90 & P95 & Max. \\
\hline \multicolumn{13}{|l|}{ Children $(\mu \mathrm{g} / \mathrm{L})$} \\
\hline All & 653 & $0.11-1.00$ & 91.1 & $1.97(1.81-2.15)$ & $<$ LOQ & 0.60 & 1.05 & 1.96 & 3.76 & 7.36 & 13.14 & 821.90 \\
\hline Belgium & 125 & 0.20 & 96.8 & $2.35(1.92-2.87)$ & $<\mathrm{LOQ}$ & 0.76 & 1.40 & 2.27 & 3.76 & 8.15 & 13.44 & 445.24 \\
\hline Denmark & 142 & 0.12 & 90.8 & $1.87(1.53-2.29)$ & $<\mathrm{LOQ}$ & 0.63 & 1.09 & 1.71 & 3.42 & 6.20 & 7.90 & 821.90 \\
\hline Luxembourg & 59 & 1.00 & 52.5 & $1.78(1.34-2.37)$ & $<\mathrm{LOQ}$ & $<\mathrm{LOQ}$ & $<$ LOQ & 1.38 & 3.33 & 5.72 & 8.28 & 18.54 \\
\hline Slovenia & 112 & 0.11 & 92.9 & $2.63(2.15-3.22)$ & $<\mathrm{LOQ}$ & 0.69 & 1.47 & 3.30 & 5.71 & 14.87 & 18.86 & 31.43 \\
\hline Spain & 118 & 0.20 & 95.8 & $1.83(1.50-2.24)$ & $<\mathrm{LOQ}$ & 0.42 & 1.10 & 1.91 & 3.59 & 7.36 & 9.84 & 21.60 \\
\hline Sweden & 97 & 0.15 & 100.0 & $1.48(1.21-1.81)$ & 0.35 & 0.58 & 0.90 & 1.31 & 2.22 & 4.14 & 6.24 & 32.40 \\
\hline \multicolumn{13}{|l|}{ Mothers $(\mu \mathrm{g} / \mathrm{L})$} \\
\hline All & 639 & $0.11-1.00$ & 90.5 & $1.78(1.62-1.94)$ & $<\mathrm{LOQ}$ & 0.46 & 1.00 & 1.94 & 3.70 & 6.70 & 11.13 & 455.62 \\
\hline Belgium & 125 & 0.20 & 100.0 & $2.55(2.07-3.15)$ & 0.30 & 0.89 & 1.41 & 2.30 & 3.94 & 7.47 & 11.63 & 455.62 \\
\hline Denmark & 143 & 0.12 & 90.9 & $2.00(1.62-2.47)$ & $<\mathrm{LOQ}$ & 0.45 & 1.00 & 2.10 & 4.16 & 8.65 & 11.45 & 105.84 \\
\hline Luxembourg & 56 & 1.00 & 44.6 & $1.63(1.21-2.19)$ & $<\mathrm{LOQ}$ & $<\mathrm{LOQ}$ & $<\mathrm{LOQ}$ & $<$ LOQ & 2.69 & 5.58 & 7.44 & 9.78 \\
\hline Slovenia & 106 & 0.11 & 81.7 & 1.37 (1.11-1.69) & $<\mathrm{LOQ}$ & $<\mathrm{LOQ}$ & 0.49 & 1.97 & 3.99 & 7.72 & 13.35 & 69.75 \\
\hline Spain & 113 & 0.20 & 96.5 & $2.04(1.65-2.52)$ & $<\mathrm{LOQ}$ & 0.41 & 1.01 & 2.26 & 5.08 & 8.64 & 12.15 & 39.80 \\
\hline Sweden & 96 & 0.15 & 100.0 & $1.30(1.05-1.60)$ & 0.23 & 0.47 & 0.79 & 1.29 & 2.18 & 3.50 & 5.02 & 6.34 \\
\hline
\end{tabular}

$\mathrm{LOQ}=$ limit of quantification; $\mathrm{GM}=$ geometric mean; 95\% CI: 95\% confidence interval; $\min .=$ minimum; and max.=maximum 
In children, the weighted geometric mean (95\% CI) for urinary BPA equaled $1.97(1.81-2.15) \mu \mathrm{g} / \mathrm{L}$ and $1.95(1.80-2.13) \mu \mathrm{g} / \mathrm{g}$ creatinine in the total European study group. In mothers, the weighted geometric mean $(95 \% \mathrm{CI})$ equaled $1.78(1.62-1.94) \mu \mathrm{g} / \mathrm{L}$ and $1.65(1.51-1.79) \mu \mathrm{g} / \mathrm{g}$ creatinine (Table SI-1), suggesting a tendency for higher levels in children compared to their mothers.

The 'raw' 90th percentile (based on six countries) for urinary BPA equaled 7.36 (95\% CI: 6.17-8.77) $\mu \mathrm{g} / \mathrm{L}$ and 7.05 (95\% CI: 5.97$8.33) \mu \mathrm{g} / \mathrm{g}$ creatinine in children and 6.70 (95\% CI: 5.73-7.83) $\mu \mathrm{g} / \mathrm{L}$ and 6.03 (95\% CI: 5.19-6.99) $\mu \mathrm{g} / \mathrm{g}$ creatinine in mothers. The weighted 90th percentile was 7.36 (95\% CI: 6.24-8.68) $\mu \mathrm{g} / \mathrm{L}$ and $7.05(5.94-8.38) \mu \mathrm{g} / \mathrm{g}$ creatinine in children and $6.56 \mu \mathrm{g} / \mathrm{L}(5.59$ $7.70)$ and $5.85(5.03-6.80) \mu \mathrm{g} / \mathrm{g}$ creatinine in mothers. The 90th percentiles of the individual countries give similar information as the average values (Table SI-2), suggesting that the distributions are comparable between the different countries. Clearly the differences in the LOQs of the analytical methods used in the different countries did not affect the distribution of the BPA values.

Several HBM studies in children and adults have been conducted in Europe, North America, and Asia, revealing the worldwide exposure to BPA (Table 3). BPA had a high detection frequency in all studies, with most of the values being >90\% throughout the studies. Also there were no clear differences in the levels in a particular country or continent (Table 3 ). When different age groups were investigated, the urinary levels of BPA tended to be higher in the youngest age category. In the US NHANES 2003-2004 study, the highest BPA levels were measured in adolescents (12-19 years), followed by children (6-11 years) and adults ( $>19$ years) (Calafat et al., 2008). However, the creatinine adjustment led to the highest BPA concentrations in children, followed by adolescents and adults (Calafat et al., 2008). In a Canadian study (Bushnik et al., 2010), BPA levels adjusted for creatinine were higher in the youngest age group (6-11 years) than in the other age categories. Similarly, German children in the youngest age category (3-5 years) had higher urinary BPA levels than children from other age categories (6-8 years, 9-11 years, and 12-14 years) (Becker et al., 2009) and in Denmark significantly higher levels were observed in children (6-10 years) compared to both older children (11-15 years) and adolescents (1621 years) (Frederiksen et al., 2013a).

\subsection{Urinary BPA: determinants of exposure}

The relationships between BPA levels and covariates resulting from univariate regression models are given in Table SI-3 for children and in Table SI-4 for mothers. Only weak associations were found; this might be partly explained by a lack of power due the relatively low sample numbers in each country, by the low variability in BPA levels, and by the difficulty to capture the factors of influence using a rather general questionnaire. It should be pointed out that DEMOCOPHES was a survey which aimed at demonstrating the feasibility of harmonizing human biomonitoring across countries.

For children, significantly higher values were observed in younger children, i.e. geometric means (95\% CI) equaled 2.15 $(1.90-2.44) \mu \mathrm{g} / \mathrm{g}$ creatinine (crt) in $6-8$ year old children vs. 1.80 $(1.61-2.02) \mu \mathrm{g} / \mathrm{g}$ crt $(p=0.04)$ in 9-11 year old children. Also, a significant effect $(p=0.03)$ of educational level was observed in children, with higher values in children from families with primary education (2.59 (2.03-3.30) $\mu \mathrm{g} / \mathrm{g} \mathrm{crt})$ compared to children from families with secondary (1.64 (1.32-2.04) $\mu \mathrm{g} / \mathrm{g}$ crt) and tertiary education (2.01 (1.83-2.21) $\mu \mathrm{g} / \mathrm{g}$ crt). In the multivariate models, a significant relationship was found between BPA levels in urine and urinary creatinine. The other variables (age and gender) were not significant. Educational level was borderline significant $(p=0.04)$, but the interpretation was not clear (Table 4 ). Possibly, the association between the urinary BPA levels and educational/social class is country dependent. While Ye et al. (2008) documented higher urinary BPA levels in the higher social class in a female Dutch population, the opposite has been seen in the general US population of NHANES 2003-2004 (Calafat et al., 2008) and a female Mexican population (Cantonwine et al., 2010).

The BPA levels in the mothers (both in $\mu \mathrm{g} / \mathrm{L}$ or $\mu \mathrm{g} / \mathrm{g}$ crt) correlated poorly but significantly with the BMI of the mother (as continuous or categorical variable - normal weight, overweight and obesity). The various correlations ranged $0.08<r<0.11$, $p<0.05, n=628$ ). When BMI is included in the multiple regression model, the association lost its significance.

Mothers who consumed canned food several times per week had significantly higher urinary BPA levels compared to mothers who consumed canned food once a week or less, i.e. the geometric mean (95\% CI) equaled 2.34 (1.88-2.91) $\mu \mathrm{g} / \mathrm{g}$ crt vs. 1.77 (1.61-1.95) $\mu \mathrm{g} / \mathrm{g}$ crt; $\mathrm{p}=0.03$. In multiple models, a significant relationship was observed with urinary creatinine (higher BPA values for higher creatinine levels; $p<0.0001$ ); time period from the last urination before urine collection (higher BPA levels with increasing collection periods; $p=0.02$ ); age of the mother (higher levels in older mothers; $p=0.002$ ) and borderline non-significant with consumption of canned food (higher levels in frequent consumers; $p=0.05$ ) (Table 4).

As a sensitivity analysis, the same multiple regression models were applied using weighting factors to adjust for the unequal sample sizes between the countries. Both in children and in mothers, the conclusions remained the same after weighting.

Other studies have also reported the influence of diet on the urinary concentrations of BPA. Quiros-Alcala et al. (2013) showed that women who consumed more than 3 fizzy drinks per day or hamburgers three times or more per week had $58 \%$ and $20 \%$ higher urinary BPA concentrations, respectively, compared with women who consumed no fizzy drinks or hamburgers. Casas et al. (2013) indicated that pregnant women who were younger, lesseducated, smoked, and who were exposed to second-hand tobacco smoke (SHS) had higher urinary BPA concentrations than others. BPA concentrations were also higher in children exposed to SHS. High consumption of canned fish during pregnancy was associated with $21 \%$ and $25 \%$ higher urinary BPA concentrations in the first and third pregnancy trimester, respectively, compared to the lowest consumption group. Further evaluation of specific BPA exposure sources in the socio-demographic group of women who smoke, are exposed to SHS, and have a low educational level is needed. Studies identifying sources of exposure would benefit from repeat BPA measurements and should use questionnaires specifically focused on dietary sources.

\subsection{Urinary BPA: correlation between children and mothers}

Spearman correlation coefficients were calculated between the individual urinary BPA levels of the mothers and the children. In total, 621 mother-child pairs had measurements of urinary BPA and were included in the analysis. The correlation between individual BPA levels in mothers and in children (in $\mu \mathrm{g} / \mathrm{L}$ ) was significant $(r=0.456$, $p<0.001$ ). Even when excluding the two extreme outliers, this correlation remained significant $(r=0.233, p<0.001)$ (Fig. SI- 1$)$. The geometric means of BPA levels (in $\mu \mathrm{g} / \mathrm{L}$ ) in each country correlated strongly between mothers and children $(r=0.96, p<0.001)$ (Fig. 2), after Slovenia was excluded as it did not follow the trends observed in the other five countries. The remarking difference between children and mothers could provide an opportunity to identify possible sources of children's exposure. However, none of the characteristics of the children, either related to food intake (canned food, convenience food, canteen food, etc.), to urine sampling (duration of collection, volume, etc.) or other study parameters deviated strongly. Therefore, the explanatory factor for the high value in children is one beyond those that are currently under investigation. 
Table 3

Overview of worldwide biomonitoring studies for BPA concentrations in urine ( $\mu \mathrm{g} / \mathrm{L}$ or $\mu \mathrm{g} / \mathrm{g} \mathrm{crt}$ ) and $\mathrm{BPA}$ intake (95\% CI) (ng/kg body weight per day).

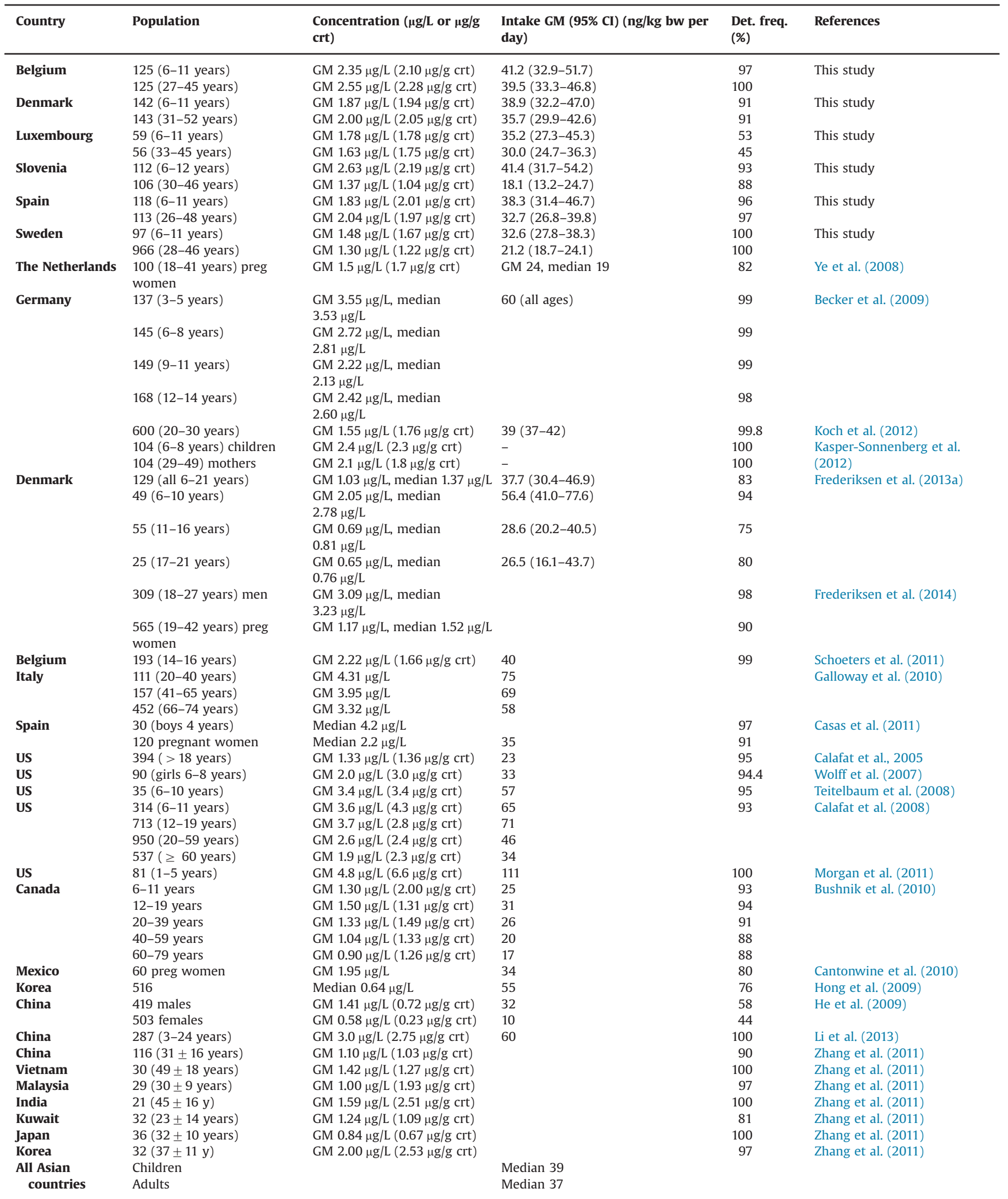

GM: geometric mean; crt: creatinine. 
Table 4

Determinants of urinary BPA $(\mu \mathrm{g} / \mathrm{L})$ : multiple linear mixed models in children and mothers.

\begin{tabular}{|c|c|c|c|c|}
\hline Parameters & Strata & Estimate $(95 \% \mathrm{CI})$ for change (multiplicative factor) & p-Value & Overall $p$-Value \\
\hline \multicolumn{5}{|l|}{ Children } \\
\hline \multicolumn{5}{|c|}{ Number of observations in model: $n=651$} \\
\hline \multicolumn{5}{|c|}{ Cluster variance: 0.0149 ( $p=0.19)$; residual variance: 1.1946 ; intra-class correlation coefficient: 1.2295} \\
\hline \multirow[t]{3}{*}{ Urinary creatinine level } & $300-900 \mathrm{mg} / \mathrm{L}$ & $0.51(0.40-0.66)$ & $<0.0001$ & $<0.0001$ \\
\hline & 900-1500 mg/L & $0.87(0.68-1.10)$ & 0.23 & \\
\hline & $1500-3000 \mathrm{mg} / \mathrm{L}$ & 1.00 & - & \\
\hline \multirow[t]{2}{*}{ Gender } & Boys & $1.03(0.87-1.22)$ & 0.73 & 0.73 \\
\hline & Girls & 1.00 & - & \\
\hline \multirow[t]{2}{*}{ Age } & 5-8 years & $1.09(0.92-1.30)$ & 0.32 & 0.32 \\
\hline & 9-12 years & 1.00 & - & \\
\hline \multirow[t]{3}{*}{ Educational level of the family } & Primary & $1.24(0.88-1.76)$ & 0.23 & 0.04 \\
\hline & Secondary & $0.81(0.65-1.00)$ & 0.05 & \\
\hline & Tertiary & 1.00 & - & \\
\hline \multicolumn{5}{|c|}{ Mothers } \\
\hline \multicolumn{5}{|c|}{ Number of observations in model: $n=639$} \\
\hline \multicolumn{5}{|c|}{ Cluster variance: 0.0559 ( $p=0.15$ ); residual variance: 0.9252 ; intra-class correlation coefficient: 5.69} \\
\hline \multirow[t]{3}{*}{ Urinary creatinine level } & $300-900 \mathrm{mg} / \mathrm{L}$ & $0.34(0.27-0.43)$ & $<0.0001$ & $<0.0001$ \\
\hline & $900-1500 \mathrm{mg} / \mathrm{L}$ & $0.65(0.52-0.82)$ & $<0.0001$ & \\
\hline & $1500-3000 \mathrm{mg} / \mathrm{L}$ & 1.00 & - & \\
\hline \multirow[t]{3}{*}{ Age } & $\leq 35$ years & $0.66(0.50-0.87)$ & 0.003 & 0.002 \\
\hline & $35-40$ years & $0.74(0.61-0.90)$ & 0.003 & \\
\hline & $>40$ years & 1.00 & - & \\
\hline \multirow[t]{3}{*}{ Urine sampling period ${ }^{\mathrm{a}}$} & $<7 \mathbf{h}$ & $0.72(0.53-0.97)$ & 0.03 & 0.02 \\
\hline & 7-9 h & $0.94(0.70-1.24)$ & 0.64 & \\
\hline & $\geq \mathbf{9 h}$ & 1.00 & - & \\
\hline \multirow[t]{2}{*}{ Consumption of canned food } & Several times per week & $1.25(0.998-1.57)$ & 0.05 & 0.05 \\
\hline & Once per week or less & 1.00 & & \\
\hline
\end{tabular}

a Period of time between the last urination and the sample collection.

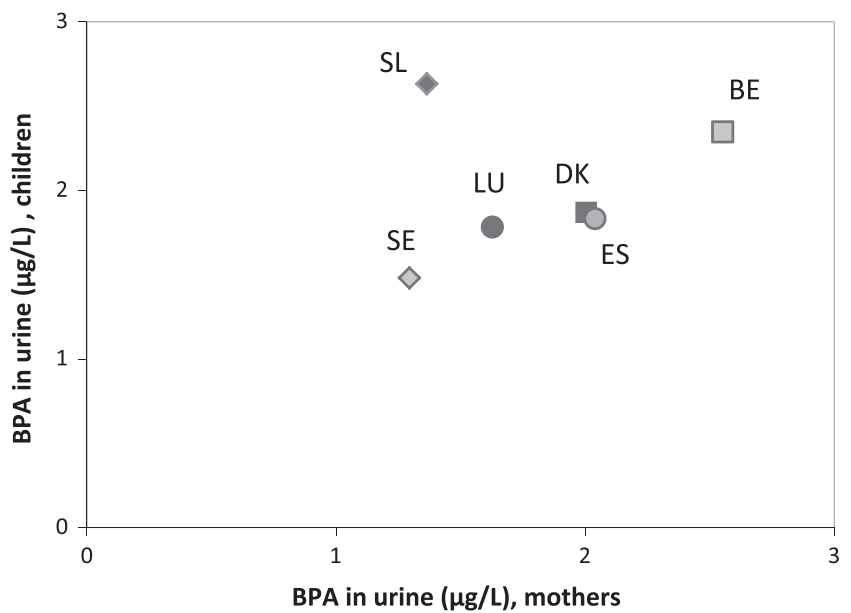

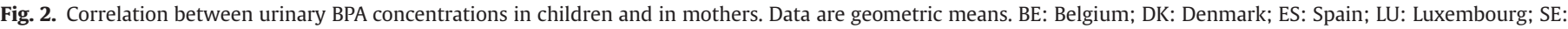
Sweden; and SL: Slovenia.

\subsection{Urinary BPA - comparison with guidance values}

The German HBM Commission defines provisional HBM values for BPA, i.e. a HBM-I of $1500 \mu \mathrm{g} / \mathrm{L}$ in children and a HBM-I value of $2500 \mu \mathrm{g} / \mathrm{L}$ in mothers (German Human Biomonitoring Commission, 2012). None of the participants had values above the HBM-I guideline, neither in children, nor in mothers. Also none of the participants had urinary concentrations of BPA above the biomonitoring equivalent (BE) value of $2000 \mu \mathrm{g} / \mathrm{L}$ proposed by Aylward et al. (2013). Of note, the provisional HBM values of the German HBM Commission have been based upon the EFSA TDI of 50,000 ng/kg bw per day and do not yet reflect the t-TDI of $5000 \mathrm{ng} / \mathrm{kg}$ bw per day proposed by EFSA in 2014, which might lead to lower HBM values.

\subsection{Intake of $B P A$}

For estimating the daily BPA intake, BPA concentrations were adjusted for daily creatinine excretion. This calculation scenario is based on the approach involving creatinine excretion described by Frederiksen et al. (2013b), Koch and Calafat (2009) and Wittassek et al. (2007). The daily intake of BPA assuming steady-state excretion is calculated using the following equation:

Intake BPA ( $\mu \mathrm{g} / \mathrm{kg}$ bw per day)

$$
=\left[U E_{\text {crea }}\left(\mu \mathrm{g} / \mathrm{g}_{\text {crea }}\right) \times C E_{\text {smoothed }}(\mathrm{g} / \text { day })\right] / B W(\mathrm{~kg})
$$

where $U_{E_{c r e a}}$ is the urinary concentration of BPA adjusted for creatinine, BW is the body weight and $\mathrm{CE}_{\text {smoothed }}$ is the $24 \mathrm{~h}$ 
urinary creatinine excretion. $\mathrm{CE}_{\mathrm{smoothed}}$ for the mothers is calculated with the following equation:

$$
\begin{aligned}
C E_{\text {smoothed }}(\mu \mathrm{g} / \text { day })= & 1.64 \times(140-\text { age }(\text { year })) \times B W(\mathrm{~kg})^{1.5} \\
& \times \text { height }(\mathrm{cm})^{0.5}
\end{aligned}
$$

where 1.64 and 140 are constants described by Frederiksen et al. (2013b) and the individual height, weight and age for each mother were used. For the children, $\mathrm{CE}_{\text {smoothed }}$ corresponded to age and sex specific average creatinine excretion levels based on data provided by Remer et al. (2002): boys aged $6-8$ years $(0.49 \mathrm{~g} /$ day) or $9-13$ years $(0.76 \mathrm{~g} /$ day $)$ and girls aged $6-8$ years $(0.45 \mathrm{~g} /$ day) or 9-13 years ( $0.72 \mathrm{~g} /$ day).

The resulting values and the corresponding descriptive statistics for children and mothers are given for each country in Table SI-5. The geometric mean and CI 95\% of BPA intake for the individual countries resulting from this calculation scenario are also given in Table 3. The trends in the intake of BPA followed the trends observed between the various countries in the urinary concentrations of BPA, with a tendency of higher intakes in children compared to adults (Table SI-5). The estimated BPA intakes in the various studies worldwide were very similar between the countries and continents (Table 3 ).

Since many factors, such as diurnal variation, changes in the rate of glomerular filtration, body mass, age, gender, health status, and external factors, such as diet, exercise, and drug use, contribute to the daily variability in creatinine output, we have calculated the intake of BPA based on a second scenario. In this 2nd calculation scenario, the urinary concentrations of total BPA $(\mu \mathrm{g} / \mathrm{L})$ in the spot samples were multiplied with $24 \mathrm{~h}$ urinary output $(\mathrm{mL})$ to obtain the daily excretion of BPA in ng/day. Since excretion of ingested BPA into urine is essentially complete in $24 \mathrm{~h}$ (Völkel et al., 2002, 2005), this was assumed to be equal to the daily intake. The estimated intake can be adjusted for body weight to obtain an exposure expressed in $\mathrm{ng} / \mathrm{kg}$ bw per day (Lakind and Naiman, 2008). Fixed volumes were used for the urinary output, e. g. $600 \mathrm{~mL}$ per day for children and $1200 \mathrm{~mL}$ per day for mothers (Lakind and Naiman, 2011). However, also urine volume is related to several factors such as liquid intake, physical exercise, and individual health and lifestyle factors. The daily intake of BPA is calculated using the following equation:

Intake BPA(ng/kg bw day)

$$
=\text { urinary conc } B P A(n g / m L) \times \text { urinary output }(m L / \text { day }) / B W(k g)
$$

Remarkably, there were very little differences observed in the BPA intakes obtained using the two calculation scenarios (Table SI5 ), suggesting the correctness of both approaches. Indeed, overall geometric means of the BPA intake of all countries (95\% CI) for the assessment via creatinine output were 38.2 (35.0-41.7) and 29.1 (26.7-31.7) ng/kg body weight per day for children and mothers, respectively, while for the assessment via fixed urinary output, they were 38.9 (35.5-42.6) and 33.6 (30.6-36.8) $\mathrm{ng} / \mathrm{kg}$ body weight per day for children and mothers, respectively.

Daily intake calculations based on biomonitoring data allow the direct comparison of individual exposures with the tolerable daily intake of 50,000 ng/kg bw per day. None of the participants had an estimated BPA intake higher than the TDI (Table SI-5). Although these dose calculations are performed using certain assumptions (e.g. daily urine volume or creatinine excretion, uniform metabolism), they reflect real exposures, where all possible exposure sources are included. However, an important outcome of these calculations is that maximum daily intakes are below the current TDI for BPA, but may exceed the newly proposed EFSA TDI of $5000 \mathrm{ng} / \mathrm{kg}$ bw per day. In other studies (summarized in Geens et al. (2012)), worst-case scenarios for young children estimated intakes of up to $11-13,000 \mathrm{ng} / \mathrm{kg}$ bw per day, which is very well in agreement with the data in this paper.

In conclusion, the current study shows that BPA exposure in Europe is widespread; in five out of six countries, more than $87 \%$ of the individuals are exposed to BPA above the LOQ. The "European reference values" of BPA showed no large differences in the urinary levels among European citizens, and among age groups. Although the current study did not focus on dietary intake, canned food consumption was an influencing factor for the mothers' levels.

\section{Acknowledgments}

The authors would like to express the greatest possible gratitude to the many people who contributed to the success of this project, which includes the members of the statistical working group and all DEMOCOPHES and COPHES project partners of the participating countries. COPHES is funded under the 7th EU framework program (DG Research No. 244237 - http://www. eu-hbm.info/cophes). DEMOCOPHES is funded $50 \%$ by LIFE+ 2009 (DG Environment - LIFE09ENV/BE000410) and the corresponding authorities in each country (http://www.eu-hbm.info/ democophes/project-partners). The additional analyses necessary for this study were not covered by the DEMOCOPHES funding. For Luxembourg, this was an in-house contribution of the CRP Gabriel Lippmann. For Spain the analysis were funded by MAGRAMA-ISCIII agreement SEG 112/10. For Belgium, this was an in-house contribution of the FPS Health, Food Chain Safety and Environment.

\section{Appendix A. Supporting information}

Supplementary data associated with this article can be found in the online version at http://dx.doi.org/10.1016/j.envres.2014.08.008.

\section{References}

Aylward, L.L., Kirman, C.R., Schoeny, R., Portier, C.J., Hays, S.M., 2013. Evaluation of biomonitoring data from the $\mathrm{CDC}$ national exposure report in a risk assessment context: perspectives across chemicals. Environ. Health. Perspect. 121, 287-294.

Becker, K., Göen, T., Seiwert, M., Conrad, A., Pick-Fuß, H., Müller, J., Wittassek, M., Schulz, C., Kolossa-Gehring, M., 2009. GerES IV: phthalate metabolites and bisphenol-A in urine of German children. Int. J. Hyg. Environ. Health 212 685-692.

Becker, K., Seiwert, M., Casteleyn, L., Joas, R., Joas, A., Biot, P., Aerts, D., Castaño, A. Esteban, M., Angerer, J., Koch, H.M., Schoeters, G., Hond, E.D., Sepai, O., Exley, K, Knudsen, L.E., Horvat, M., Bloemen, L., DEMOCOPHES consortium, KolossaGehring, M., 2014. A systematic approach for designing a human biomonitoring study for Europe. Int. J. Hyg. Environ. Health 217, 312-322.

Bushnik, T., Haines, D., Levallois, P., Levesque, J., 2010. Lead and bisphenol-A concentrations in the Canadian populations. Stat. Can. Health Rep. 21, 7-18.

Calafat, A.M., Kuklenyik, Z., Reidy, J.A., Caudill, S.P., Ekong, J., Needham, L.L., 2005. Urinary concentrations of bisphenol A and 4-nonylphenol in a human reference population. Environ. Health. Perspect. 113, 391-395.

Calafat, A.M., Ye, X.Y., Wong, L.Y., Reidy, J.A., Needham, L.L., 2008. Exposure of the US population to bisphenol-A and 4-tertiary-octylphenol: 2003-2004. Environ. Health Perspect. 116, 39-44.

Cantonwine, D., Meeker, J.D., Hu, H., Sánchez, B.N., Lamadrid-Figueroa, H., MercadoGarcía, A., Fortenberry, G.Z., Calafat, A.M., Téllez-Rojo, M.M., 2010. Bisphenol-A exposure in Mexico city and risk of prematurity: a pilot nested case control study. Environ. Health 9, 62.

Casas, L., Fernandez, M.F., Llop, S., Guxens, M., Ballester, F., Olea, N., Iruzun, M.B. Rodriguez, L.S.M., Riaño, I., Tardon, A., Vrijheid, M., Calafat, A.M., Sunyer, J., 2011. Urinary concentrations of phthalates and phenols in a population of Spanish pregnant women and children. Environ. Int. 37, 858-866.

Casas, M., Valvi, D., Luque, N., Ballesteros-Gomez, A., Carsin, A.-E., Fernandez, M.F, Koch, H.M., Mendez, M.A., Sunyer, J., Rubio, S., Vrijheid, M., 2013. Dietary and socio-demographic determinants of bisphenol-A urine concentrations in pregnant women and children. Environ. Int. 56, 10-18.

Casteleyn, L., Dumez, B., Becker, K., Kolossa-Gehring, M., Den Hond, E., Schoeters, G., Castaño, A., Koch, H.M., Angerer, J., Esteban, M., Exley, K., Sepai, O., Bloemen, L., 
Horvat, K., Knudsen, L.E., Joas, A., Joas, R., Biot, P., Katsonouri, A., Hadjipanayis, A., Cerna, M., Krskova, A., Schwedler, G., Fiddicke, U., Mørck, T.A., Rudnai, P., Kozepesy, S., Mulcahy, M., Mannion, R., Gutleb, A.C., Fischer, M., Ligocka, D. Jakubowski, M., Namorado, S., Reis, M.F., Lupsa, I.R., Gurzau, A.E., Halzlova, K., Jajcaj, M., Mazej, D., Snoj Tratnik, J., Posada, M., López, E., Berglund, M., Larsson, K. Lehmann, A., Crettaz, P., Aerts, D., 2014. A pilot study on the feasibility of the European human biomonitoring framework and program: challenges and opportunities. Environ. Res. (Submitted for publication).

EFSA, 2014. European Food Safety Authority. 〈http://www.efsa.europa.eu/en/con sultations/call/140117.pdf).

Fox, J., 1991. (Ed.). Regression Diagnostics: an Introduction. Sage, CA.

Frederiksen, H., Aksglaede, L., Sorensen, K., Nielsen, O., Main, K.M., Skakkebæk, N.E. Juul, A., Andersson, A.-M., 2013a. Bisphenol-A and other phenols in urine from Danish children and adolescents analyzed by isotope diluted TurboFlow-LCMS/MS. Int. J. Hyg. Environ. Health 216, 710-720.

Frederiksen, H., Kolstrup Søgaard Nielsen, J., Aarøe Mørck, T., Winton Hansen, P. Fangel Jensen, J., Nielsen, O., Andersson, A.-M., Knudsen, L.E., 2013b. Urinary excretion of phthalate metabolites, phenols and parabens in rural and urban Danish mother-child pairs. Int. J. Hyg. Environ. Health 216, 772-783.

Frederiksen, H., Jensen, T.K., Jørgensen, N., Kyhl, H.B., Husby, S., Skakkebæk, N.E. Main, K.M., Juul, A., Andersson, A.M., 2014. Human urinary excretion of nonpersistent environmental chemicals: an overview of Danish data collected 2006-2012. Reproduction 147, 555-565.

Galloway, T., Cipelli, R., Guralnik, J., Ferrucci, L., Bandinelli, S., Corsi, A.M., Money, C. McCormack, P., Melzer, D., 2010. Daily bisphenol-A excretion and association with sex hormone concentrations: results from the InCHIANTI adult population study. Environ. Health Perspect. 118, 1603-1608.

Geens, T., Goeyens, L., Covaci, A., 2011. Are potential sources for human exposure to Bisphenol-A overlooked? Int. J. Hyg. Environ. Health 214, 339-347.

Geens, T., Aerts, D., Berthot, C., Bourguignon, J.P., Goeyens, L., Lecomte, P., MaghuinRogister, G., Pironnet, A.M., Pussemier, L., Scippo, M.L., Van Loco, J., Covaci, A. 2012. A review of dietary and non-dietary exposure to bisphenol-A. Food Chem. Toxicol. 50, 3725-3740.

German Human Biomonitoring Commission, 2012. Stoffmonographie bisphenol-A (BPA) - referenz- und human-biomonitoring-(HBM)-werte für BPA im urin Bundesgesundheitsblatt, Gesundheitsforschung, Gesundheitsschutz 55 (9) 1215-1231.

He, Y., Miao, M., Herrinton, L.J., Wu, C., Yuan, W., Zhou, Z., Li, D.K., 2009. Bisphenol-A levels in blood and urine in a Chinese population and the personal factors affecting the levels. Environ. Res. 109, 629-633.

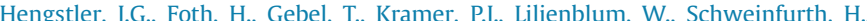
Volkel, W., Wollin, K.M., Gundert-Remy, U., 2011. Critical evaluation of key evidence on the human health hazards of exposure to bisphenol-A. Crit. Rev. Toxicol. 41, 263-291.

Hong, Y.C., Park, E.Y., Park, M.S., Ko, J.A., Oh, S.Y., Kim, H., Lee, K.H., Leem, J.H., Ha, E. H., 2009. Community level exposure to chemicals and oxidative stress in adult population. Toxicol. Lett. 184, 139-144.

Kasper-Sonnenberg, M., Koch, H.M., Wittsiepe, J., Wilhelm, M., Fromme, H., 2012. Determination of bisphenol-A in urine from child-mother pairs - results from the Duisburg birth cohort study. J. Toxicol. Environ. Health. A 75, 429-437.

Koch, H.M., Calafat, A.M., 2009. Human body burdens of chemicals used in plastic manufacture. Philos. Trans. R. Soc. Lond. B.: Biol Sci. 364, 2063-2078.

Koch, H.M., Kolossa-Gehring, M., Schröter-Kermani, C., Angerer, J., Brüning, T., 2012 Bisphenol-A in $24 \mathrm{~h}$ urine and plasma samples of the German Environmenta Specimen Bank from 1995 to 2009: a retrospective exposure evaluation. J. Exp. Sci. Environ. Epidemiol. 22, 610-616.

Lakind, J.S., Naiman, D.Q., 2008. Bisphenol-A (BPA) daily intakes in the United States: estimates from the 2003-2004 NHANES urinary BPA data. J. Exp. Sci. Environ. Epidemiol. 18, 608-615.

Lakind, J.S., Naiman, D.Q., 2011. Daily intake of bisphenol-A and potential sources of exposure: estimates from the 2005-2006 National Health and Nutrition Examination Survey. J. Exp. Sci. Environ. Epidemiol. 21, 272-279.

Li, X., Ying, G.G., Zhao, J.L., Chen, Z.F., Lai, H.J., Su, H.C., 2013. 4-nonylphenol, bisphenol-A and triclosan levels in human urine of children and students in China and the effects of drinking these bottles materials on levels. Environ. Int. $52,81-86$

Morgan, M.K., Jones, P.A., Calafat, A.M., Ye, X., Croghan, C.W., Chuang, J.C., Wilson, N. K., Clifton, M.S., Figueroa, Z., Sheldon, L.S., 2011. Assessing the quantitative relationship between preschool children's exposure to bisphenol-A by route and urinary biomonitoring. Environ. Sci. Technol. 45, 5309-5316.

Neter, J., Wasserman, W., Kutner, M.H., 1996. Applied Linear Statistical Models. McGraw-Hill, New York.

Quiros-Alcala, L., Eskenazi, B., Bradman, A., Ye, X.Y., Calafat, A.M., Harley, K., 2013. Determinants of urinary bisphenol-A concentrations in Mexican/MexicanAmerican pregnant women. Environ. Int. 59, 152-160.

R Development Core Team, 2012. R: A Language and Environment for Statistical Computing. R Foundation for Statistical Computing, Vienna, Austria, ISBN: 3900051-07-0 〈http://www.R-project.org/〉.

Remer, T., Neubert, A., Maser-Gluth, C., 2002. Anthropometry-based reference values for 24-h urinary creatinine excretion during growth and their use in endocrine and nutritional research. Am. J. Clin. Nutr. 75, 561-569.

Schindler, B.K., Esteban, M., Koch, H.M., Castano, A., Koslitz, S., Cañas, A., Casteleyn, L., Kolossa-Gehring, M., Schwedler, G., Schoeters, G., Hond, E.D., Sepai, O., Exley, K., Bloemen, L., Horvat, M., Knudsen, L.E., Joas, A., Joas, R., Biot, P., Aerts, D. Lopez, A., Huetos, O., Katsonouri, A., Maurer-Chronakis, K., Kasparova, L., Vrbík, K., Rudnai, P., Naray, M., Guignard, C., Fischer, M.E., Ligocka, D., Janasik, B., Reis, M.F. Namorado, S., Pop, C., Dumitrascu, I., Halzlova, K., Fabianova, E., Mazej, D. Tratnik, J.S., Berglund, M., Jönsson, B., Lehmann, A., Crettaz, P., Frederiksen, H., Nielsen, F., McGrath, H., Nesbitt, I., De Cremer, K., Vanermen, G., Koppen, G., Wilhelm, M., Becker, K., Angerer, J., 2014. The European COPHES/DEMOCOPHES project: towards transnational comparability and reliability of human biomonitoring results. Int. J. Hyg. Environ. Health 217, 653-661.

Schoeters, G., Colles, A., Den Hond, E., Croes, K., Vrijens, J., Baeyens, W., Nelen, V. Van de Mieroop, E., Covaci, A., Bruckers, L., Van Larebeke, N., Sioen, S., Morrens, B., Loots, I., 2011. The Flemish Environment and Health Study (FLEHS) - second survey (2007-2011): establishing reference values for biomarkers of exposure in the Flemish population. In: Knudsen, L.E., Merlo, D.F. (Eds.), Biomarkers and Human Biomonitoring Volume 1: Ongoing Programs and Exposures. Royal Society of Chemistry, Letchworth, pp. 135-165.

Teeguarden, J.G., Hanson-Drury, S., 2013. A systematic review of bisphenol A "low dose" studies in the context of human exposure: a case for establishing standards for reporting "low-dose" effects of chemicals. Food Chem. Toxicol. 62, 935-948.

Teitelbaum, S.L., Britton, J.A., Calafat, A.M., Ye, X., Silva, M.J., Reidy, J.A., Galvez, M.P., Brenner, B.L., Wolff, M.S., 2008. Temporal variability in urinary concentrations of phthalate metabolites, phytoestrogens and phenols among minority children in the United States. Environ. Res. 106, 257-269.

Vandenberg, L.N., Hauser, R., Marcus, M., Olea, N., Welshons, W.V., 2007. Human exposure to bisphenol A (BPA). Reprod. Toxicol. 24, 139-177.

Völkel, W., Colnot, T., Csanady, G.A., Filser, J.G., Dekant, W., 2002. Metabolism and kinetics of bisphenol-A in humans at low doses following oral administration. Chem. Res. Toxicol. 15, 1281-1287.

Völkel, W., Bittner, N., Dekant, W., 2005. Quantitation of bisphenol-A and bisphenol-A glucuronide in biological samples by high performance liquid chromatography-tandem mass spectrometry. Drug Metab. Dispos. 33, 1748-1757.

WHO, 1996. Biological Monitoring of Chemical Exposure in the Workplace. World Health Organization, Geneva.

Wittassek, M., Heger, W., Koch, H.M., Becker, K., Angerer, J., Kolossa-Gehring, M., 2007. Daily intake of di(2-ethylhexyl) phthalate (DEHP) by German children - a comparison of two estimation models based on urinary DEHP metabolite levels. Int. J. Hyg. Environ. Health 210, 35-42.

Wolff, M.S., Teitelbaum, S.L., Windham, G., Pinney, S.M., Britton, J.A., Chelimo, C., Godbold, J., Biro, F., Kushi, L.H., Pfeiffer, C.M., Calafat, A.M., 2007. Pilot study of urinary biomarkers of phytoestrogens, phthalates, and phenols in girls. Environ. Health Perspect. 115, 116-121.

Ye, X., Pierik, F.H., Hauser, R., Duty, S., Angerer, J., Park, M.M., Burdorf, A., Hofman, A., Jaddoe, V.W.V., Mackenbach, J.P., Steegers, E.A.P., Tiemeier, H., Longnecker, M.P., 2008. Urinary metabolite concentrations of organophosphorus pesticides, bisphenol-A, and phthalates among pregnant women in Rotterdam, the Netherlands: the generation R study. Environ. Res. 108, 260-267.

Zhang, Z., Alomirah, H., Cho, H.S., Li, Y.F., Liao, C., Minh, T.B., Mohd, M.A., Nakata, H., Ren, N. Kannan, K., 2011. Urinary bisphenol-A concentrations and their implications for human exposure in several Asian countries. Environ. Sci. Technol. 45, 7044-7050. 